\title{
Semantic Link with the Natural Environment: Sustainable and Healthy Artificial Environments for Hot-Humid and Warm-Humid Climates
}

\author{
Ahmet Kochan ${ }^{1}$, Altay Colak ${ }^{1, *}$, Tolga Uzun ${ }^{1}$, Ayberk N. Berkman ${ }^{2}$, Mustafa Yegin ${ }^{1}$, Erkan \\ Gunes $^{3}$ \\ ${ }^{1}$ Cukurova University, Faculty of Engineering and Architecture, Department of Architecture, Adana Turkey \\ ${ }^{2}$ Cukurova University, Faculty of Economics and Administrative Sciences, Department of Economics \\ ${ }^{3}$ Eser Architecture, Mersin, Turkey \\ *Corresponding author Tel: +90 3223386084-2921, E-mail: acolak@cu.edu.tr
}

\begin{abstract}
Architectural artificial environment; as a joint product of imagination and technical information and as a combination of ecological, social, political, aesthetical and moral values, is the balancing epistemological systematic for ecology, economics and society which comprises of the future generations and all other living creatures. In ecological architecture, it is essential to design artificial environment as an artificial ecological system. This study asserts regional principles for different climate zones and environmental conditions by determining environmentally-conscious general design principles of ecological and sustainable public housing design. The significance and authenticity devolved on ecological and sustainable public housings and settlements on local, regional and global scales are discussed. As a result, in the light of the foregoing information given on ecological and sustainable process model and climate-weighted ecological and sustainable social public housing design model, related suggestions are made.
\end{abstract}

Keywords: Sustainability, Healthy Artificial Environment, Healthy and Sustainable Process Model.

\section{Introduction}

In today's world, energy production and consumption are among the most important criteria for development. Since the biggest portion of daily activities occurs in the building, the number of buildings and the level of energy consumption are correlated. However, existing and newly-constructed buildings are the main reasons for some of the major problems of our present and future such as environmental pollution and exhaustion of natural resources. Especially in the $20^{\text {th }}$ century, the effects of both industrial and technological power of mankind over nature have reached its highest levels, even to the extent that it might have destroyed the life on life as we know it.

Incidents such as global warming, thinning of ozone layer, glacier meltdown, diminishing of forest lands, air and water pollution, extinction of species, etc. indicate that today's life style is not only disappointing, but also far away from being an inspiration for the future. Especially, by considering imperative revision of the $20^{\text {th }}$ century's life style, adoption and development of a life style with less energy usage in daily routine and guidance of the society toward that direction are necessary within the scope of interdisciplinary studies. In this context, architecture as an effective discipline for both nature and human life assumes fundamental duties. While human-centric design in architecture was subject to change, environmental consciousness and harmony with nature had become the main criteria for success.

Considering the usage percentages of global resources in buildings, housings clearly take place in life style of the $21^{\text {th }}$ century's information society as prominent means for achieving ecological and sustainable objectives. 
Table 1. The Usage Percentages of Global Resources in Buildings and The Percentage of Global Pollution Level caused by Buildings. (1)

\begin{tabular}{lc}
\hline Resource & 2. \% of Usage \\
& \\
\hline Energy & $50 \%$ \\
\hline Water & $42 \%$ \\
\hline Materials & $50 \%$ \\
\hline Agricultural Areas & $48 \%$ \\
\hline Coral Reefs & $50 \%$ \\
\hline
\end{tabular}

\begin{tabular}{lc}
\hline Pollution & $\begin{array}{c}\text { Relation to } \\
\text { Building }\end{array}$ \\
\hline Air Quality (Urban) & $24 \%$ \\
\hline Global Warming Gases & $50 \%$ \\
\hline Drinking Water Pollution & $40 \%$ \\
\hline Superficial Solid Waste & $20 \%$ \\
\hline CFCs/HCFCs & $50 \%$ \\
\hline
\end{tabular}

Historically, housing is an organized pattern of communication, interaction, space, time and significance. On the one hand, it reflects the characteristics, life styles, behavioral codes, ecological choices, images and time-space taxonometries of ethnic groups it belongs to, and on the other hand it reflects personality and concession of the individual via its users' essential images and propensity of self-expression (2). Housing, a by-product of settled living culture, has survived in different building forms as the result of different climate conditions, cultures in different regions. Artificial environment of traditional architecture had been an output of the balance of the challenge between nature and mankind. However, migration toward urban areas, due to labor demand of industrial system, attraction of urban life and various other factors have eventually disrupted that balance. Public housing became the solution for sheltering needs emerged due to industrialization, overpopulation and urbanization. However, as a result of new building materials, new construction techniques and over-consumption of resources especially with the misconception of cheap and seemingly inexhaustible fossil-based energy sources; hazardous wastes, environmental pollution and artificial environments that fail to meet the users' needs came into existence. Thus, today's housing acquisition policies have reached a turning point. The aim of increasing life quality of housing and environment is on the agenda, rather than the mere effort of providing a huge number of community members with housing facilities. Evidently, related studies and energy issues in accordance with mission they undertake are amongst the most important facts of the future.

\section{Sustainable Society and Artificial Environments}

Throughout the history, mankind had experienced mainly 3 revolutionary transitions: the first and the longest one; transition to settled life as an agricultural society, the second; the Industrial Revolution, and the third one; transition to an information society(3). Being an information society in the $21^{\text {th }}$ century requires innovation and nurturing of new multidisciplinary approaches and applicable models aiming for sustainable development for both present and future generations. Society / Economy / Ecology are 3 important components of Sustainable Society Structure (Fig. 1).

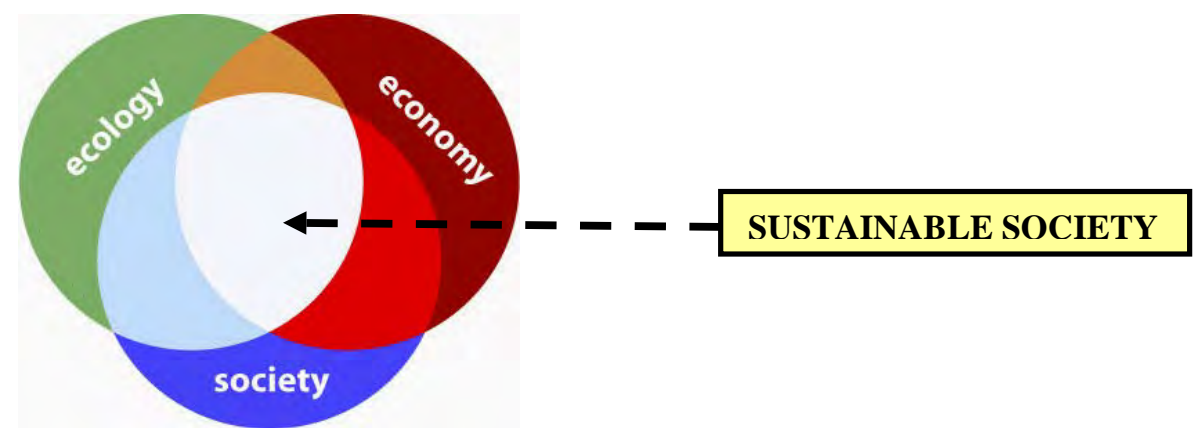

Fig. 1. Sustainable Society Structure (4) 
Environmentally-conscious and sustainable artificial environments go through a long process to be formed, from the designing stage that begins with a preliminary sketch to the end of the physical life of building. Architectural artificial environments not only serve to meet sheltering needs of the society, but they also appear as mutual products of imagination, technical information and a combination of ecological, social, political, aesthetical and moral values. They are the balancing epistemological systematic for ecology, economics and society which comprises of the future generations and all other living creatures. They are formed with the moral necessity that requires the society to act as a whole for a common purpose (5).

Considering the role of environmentally-conscious architecture in solving global ecological and energy problems, 3 di mension of the mission undertaken by sustainable artificial environment designs are prominent; economical dimension, social dimension and ecological dimension. "Rationalistic and Salutary Sustainable Artificial Environments" are present at the common denominator of ecology, society and economy, with an interactive and conscious balance, (Fig. 2).

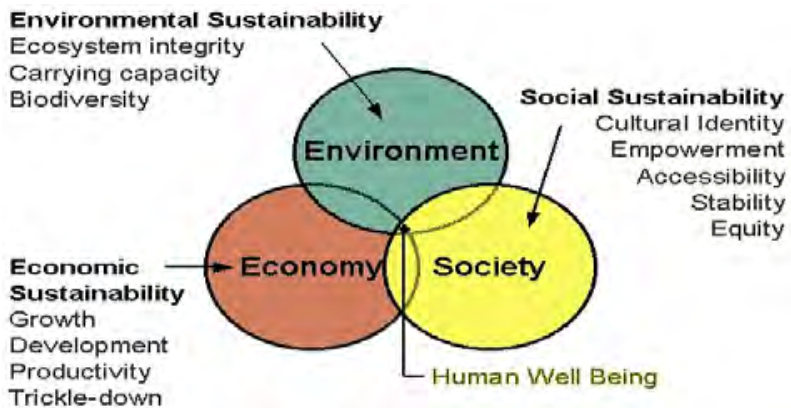

Fig. 2. Rationalistic and Salutary Sustainable Artificial Environment Model (6)

\section{Methodology}

\subsection{Ecological Housing and Realization Potential for Sustainability}

Designing, construction and usage of buildings take a long process and continuous consumption, accumulation of wastes are natural consequences. Therefore, the effects of architecture on ecological problems are present at the stages of designing, production, usage and until the end of physical life of architectural output. Nonetheless, in today's world it is almost mandatory to find new solutions in order to minimize adverse effects, or at least to keep them within reasonable boundaries. Architectural artificial environment should be viewed and designed as an artificial ecological system. Deterioration of ecological environment, as a concrete factor closely related to individual and societal welfare, has both quantitative and qualitative adverse effects on society. In order to get rid of those adverse effects and to develop ecological consciousness, artificial environment design should abide by a series of criteria. These criteria are multi-dimensional social and physical components variable upon time and location conditions, covering the whole process from the designing stage of the building to demolition phase.

As of ecological and sustainable studies in general, the following are prerequisites for sustainable environment;

- Rational, productive and minimal resource consumption,

- Usage of recyclable materials and renewable resources,

- Conservation of energy stocks, usage of renewable energy sources which do not cause environmental pollution and,

- Recycling of wastes (7).

Pilot projects introduced as ecological and sustainable approaches are based on mainly 5 basic principles; (7) 
i. Salutary Artificial Environment: Harmony with topography is restored, the former natural habitat is revived, and formation of an artificial ecosystem is aimed. Building materials with no toxic raw materials and hazardous gases and construction systems are used. Waste control and recycling are applied without polluting water and air.

ii. Sufficient and Efficient Energy Systems: Necessary precautions should be taken in order to keep energy usage at the lowest level for providing suitable vital conditions.

Heating, lighting and cooling systems are made of energy-efficient methods and products. Renewable energies are utilized as much as possible in active, passive or mixed systems.

iii. Environmentally-conscious Building Materials: In production, application, building materials and products with no hazardous waste that require less-energy are used. Usage of natural materials such as wood requires maximum diligence for energy efficiency. Especially, recyclable products and systems are used.

iv. Environmentally-conscious Form: Building forms and space organization are designed according to the structure of location and climate characteristics of the region. Ecological structure is respected. Interior comfort conditions are provided via rational and productive use of energy. Form is designed in such a way that a harmonic nexus between the user and nature is established.

v. Smart Design: Space usage, circulation, building form, mechanical systems and construction are designed to maintain productive, swift, harmonic and durable operation.

\subsection{Ecological and Sustainable Housing Design}

Sustainable, environmentally-conscious and energy-efficient public housing design can be defined under 2 headlines; unchanged 'General Principles', and 'Regional Principles' that are variable upon climate conditions of the region (8).

\subsubsection{General Principles}

General principles of sustainable public housing design also include some basic principles that are valid for all geographical areas. Despite different conditions; these are constant, sustainable and energy-efficient design decisions, which cover design, construction, usage and all other stages throughout the entire physical life of public housings. Following are 10 Basic General Principles;

i. Conception System and Design Principles; Environmental consciousness and energy conservation come into being on the table during the designing stage prior to physical existence of the building.

ii. Ecological Artificial Environment Design and Location Choice; Location choice, accurate interaction with environment, energy conservation and environmental consciousness are among the most crucial phases in sustainable public housing design. Design decisions are subject to have regional differences in accordance with climate conditions of the location.

iii. Construction and Resource Management; Resource and energy consumptions during construction phase have a huge share in total consumption. Thus, this phase has great importance for studies with the aim of sustainability in public housings.

iv. Building Envelope and Building Geometry; Building envelope and building geometry put forth the semantic nexus with natural habitat for consideration. Design decisions are subject to change according to regional differences.

v. Space Organization; Space organization in housing is one of the most important factors which affect the users' health and productivity. Living culture is determinant for interior function. Designing is subject to differ according to regional climate conditions of the location.

vi. Choice of Building Material and its Adequacy in terms of Building Physics; The concept of sustainable public housing combines all environmentally-conscious and energy 
efficient methods throughout the entire stages of the building; from designing to the end of its physical life. Usage of sustainable and environmentally-conscious materials and products is one of the most important phases. Appropriate material choice in accordance with regional climate conditions is essential for success.

vii. Air-conditioning Systems; Air-conditioning of housings is one of the most important phases for providing the users' health and comfort, and for managing resource usage and energy consumption. Air-conditioning systems would differ according to regional climate conditions.

viii. Users' Comfort Needs; The concept of sustainable public housing aims to meet the users' comfort expectation at maximum level. Meeting the needs without destroying the environment is top priority.

ix. Waste Management; The adverse effects of wastes on natural environment necessitate sustainable and ecological design. Thus, waste management becomes a preferential objective of design. As a result, unmanageable wastes inflict damage to natural life along with human health.

x. Natural Life and Sustainable Society; Mankind cannot survive without nature. Therefore, the faster we destroy our natural environment, the sooner we approach to our own extinction.

\subsubsection{Regional Principles}

There are many different climate zones due to various geographic factors such as solar radiation reception, topographic structure and flora. Regional principle are sustainable and environmentally-conscious design decisions which contain regional differences on de sign, construction, usage and physical life of public housing resulting from variable climate conditions. Different climate conditions cause public housing and artificial environment location choices to be unique to the current region by the help of architectural differences in building envelope, building geometry, space organization, building material and airconditioning systems. General principles; such as 'Location Choice and Ecologic Artificial Environment Design', 'Building Envelope and Building Geometry', 'Space Organization', 'Choice of Building Materials and their Adequacy in terms of Building Physics' and 'Airconditioning Systems', contain some additional precautionary measures and principles in accordance with climate conditions of the location (Fig. 3).

\section{Discussion}

The rise of ecological and sustainable buildings, as an indication of technological improvement in Today's information society, does not only aim to meet people's sheltering needs. Ecological and sustainable design is not merely an arbitrary architectural interpretation from a group of environmentally-conscious architects. Being ecological and sustainable requires taking lessons from environmental catastrophes caused by the $19^{\text {th }}$ century's Industrial Revolution and the $20^{\text {th }}$ century's human-centric life style. A well-planned design is not the final phase for sustainability. It begins with design decisions on the table and continues until the end of physical life of the building. This process can be broken down into 8 phases;

i. Understanding the Location: Ecological and sustainable design begins with selfdescription of its concrete and abstract value via detailed analysis of the location.

ii. Understanding Natural Process-Respect to Nature: Ecology has a $\mathrm{n}$ atural balance which provides and protects the continuity of life on earth. There is no place for waste in natural life; the by-product of a living organism serves as a food resource of another. Thus, 
artificial environments formed by architecture should act as components of natural systems in order to maintain the continuity of life.

iii. Understanding the People: Architect should be familiar with the users who will be residing within the artificial environment that he/she designs. The users' habits, needs, sentiments, beliefs, cultures etc. should be analyzed and design should be modified in accordance with obtained information.

iv. Interdisciplinary Interaction / Team Work: Sustainable design is a conscious integration of architecture with electrical, mechanical and structural engineering and sociologists. Designer should interact with all other disciplinary fields, regard all related opinions and provide common solutions to problems.

v. Construction Planning: It begins with application of architecture's concrete effects on environment to designed output. Adverse effects of construction sites on the environment such as water, air and noise pollution are minimized and consumption of resources are controlled, so that the damaged portion of nature would be restored.

vi. Planning Tenancy Process: Resource consumption and wastes reach their highest levels during tenancy process of buildings. Systems with minimum adverse effects to environment are designed and used for meeting the needs, comfort conditions. Renewable energy sources are utilized at the highest possible level, while fossil fuel usage and wastes are controlled and minimized. Low-cost with high-efficiency is aimed.

vii. Conscious Society/Global Action: Success of ecological and sustainable studies depends directly on cooperation of societies and a global participation. Especially the countries which cause more global pollution should be more responsible for taking active roles in these studies.

viii. Foreseeing the Future: It is essential to preserve resources to be passed on to usage of future generations. For this purpose, rational and planned consumption of resources and recyclable material choice are foreseen. At the designing stage, physical lives of the buildings and demolition phases are predicted.

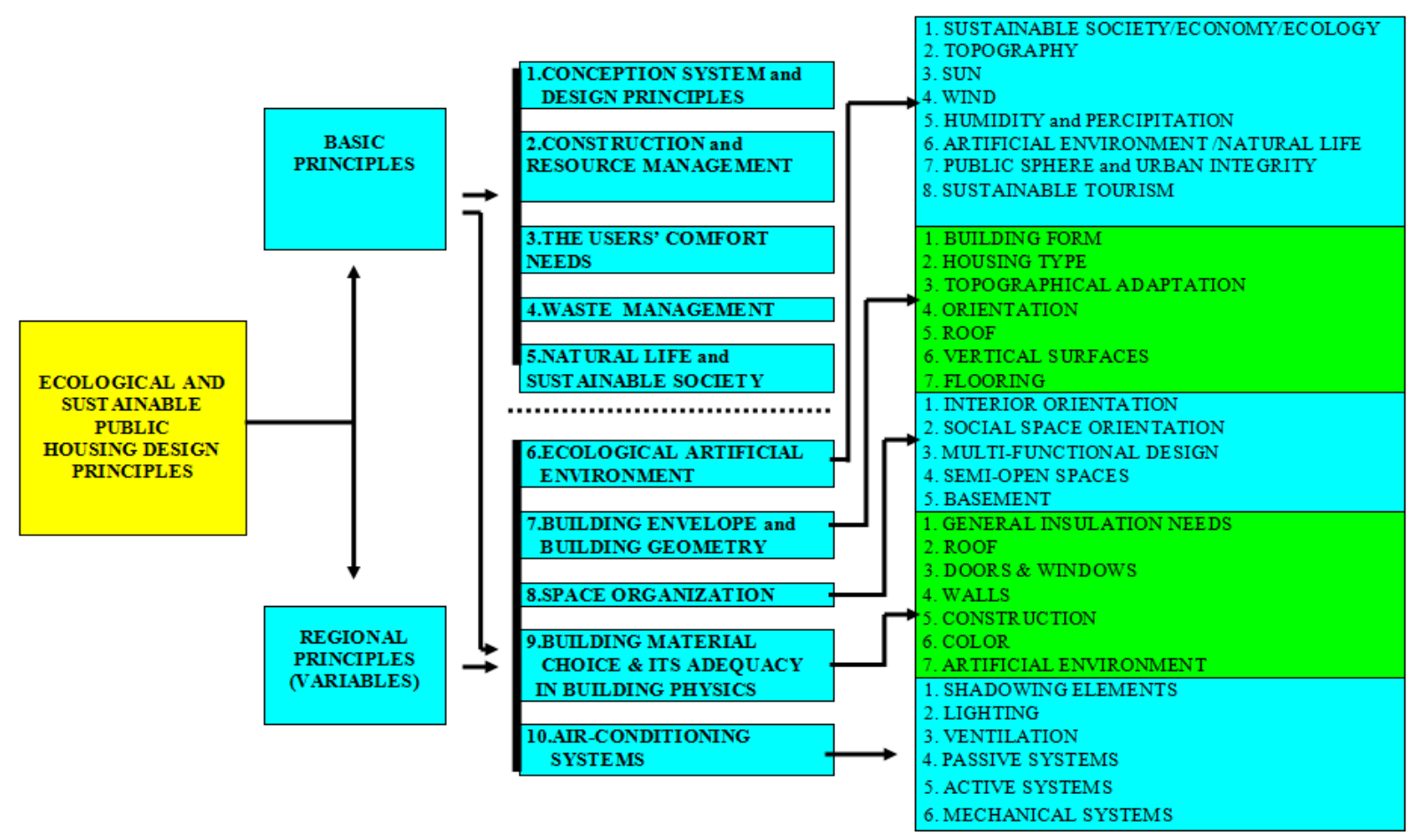

Fig. 3. Climate-Weighted Design Model in Ecological and Sustainable Public Housing (8) 


\section{Conclusions}

Ecological and sustainable design is neither merely a style nor an architectural conception of a group of architects. Being ecological and sustainable is nominated as life style and understanding of the $21^{\text {st }}$ century's information society accessorized with past experiences from environmental disasters caused by the 19th century's Industrial Revolution and the 20th century's economy-based and human-centric industrial society. After all, it is well-understood that human-kind would not exist without nature. That is to say, the faster we destroy our natural environment, the sooner we go extinct. Ecological and sustainable approaches aim to balance social, economic and environmental aspects of our present and future actions. The undertaken mission concerns a matter of existence or extinction, beyond any further achievement.

The users should be aware of characteristics and purposes of organizational, structural and factual design which brings existential integrity to architectural objects in architectural ecological artificial environment by the help of ecological and sustainable public housing design. For this purpose, every environmentally-conscious architectural innovation should be set up along with all its objective values with their abstract and concrete realities on sound basis. Local-regional-global significance and realities of ecological and sustainable public housing toward today's information society and future generations, namely, relative realities can be examined in 4 categories;

i. Existential Reality; is simply mankind's need for sheltering and protection against outer nature conditions. This reality involves the interdependence between the living organism and its habitat and sentimental and sensorial connections with domicile.

ii. Material Reality; is the provision of all necessities and objective needs as the basis for sensual perception and biological convenience in order to provide the most appropriate conditions for the users' health, productivity and comfort.

iii. Ideal Reality; is the formation of an artificial ecological environment along with architectural artificial environment by making appropriate design decisions and maintaining a balanced interaction between artificial environment and natural environment.

iv. Basic Reality; is the formation of environmentally-conscious and sustainable life style for the $21^{\text {st }}$ century by establishing a rationalistic balance with respect to ecology-societyeconomy triangle within local, regional and global dimensions.

\section{References}

[1] B. EDWARDS, Green Architecture, Architectural Design 2001, Volume 71, Issue 4, pp. 30.

[2] Ş.Ö. GÜR, Doğu Karadeniz Örneğinde Konut Kültürü,Yapı Endüstri Merkezi Yayınları, Istanbul, Nisan 2000, pp. 11.

[3] Z. UTKUTUĞ, Mimarlık: Yaşamın İçinde Bir Serüven, Yeni Ufuklara, Bilim Ve Teknik, TÜBİTAK, Kasım 2002, pp. 22.

[4] www.clearcreekwater.org/watershed-management.html

[5] A. KOÇHAN, Sürdürülebilir Gelecek İçin Ekolojik Tasarım, Yap1 249, Ağustos 2002, pp. $45-53$.

[6] http://www.arch.hku.hk/research/BEER/sustain.htm

[7] A. KOÇHAN, Doğal Çevreyle Kurulan Anlamsal Bağ: Sürdürülebilir Toplu Konut 
Tasarım1, Yap1 256, Mart 2003, pp. 49 - 55.

[8] A. KOÇHAN, İklimsel Bölgelere Göre Ekolojik ve Sürdürülebilir Toplu Konut Tasarımında Düşünce Sistematiği, KTÜ Fen Bilimleri, Trabzon 2003. 